Artigo Original

\title{
Lazer na terceira idade: desenvolvimento humano e qualidade de vida
}

\author{
Guilherme Mori ${ }^{1}$ \\ Luciene Ferreira da Silva $^{11}$ \\ ${ }^{1}$ Faculdade de Ciências. UNESP - Univ Estadual Paulista, Campus de Bauru, \\ Departamento de Educação, Grupo de Estudos e Pesquisas em Lazer, Bauru, SP, Brasil
}

\begin{abstract}
Resumo: $\mathrm{O}$ artigo teve como objetivo compreender a visão sobre o lazer e o entendimento que os idosos possuíam sobre os seus benefícios, dado o quadro de ociosidade dessa população. Foi utilizada uma amostra de sujeitos residentes na cidade de Bauru-SP, com idade igual ou superior a cinqüenta anos, de ambos os sexos e de classe desfavorecida economicamente. Utilizou-se de pesquisa bibliográfica, documental e de campo. Foi desenvolvido um projeto de intervenção que visou a educação para o lazer. Chegou-se a conclusão que são necessárias políticas públicas e profissionais qualificados para a construção de projetos e de equipamentos que expandam o Lazer, difundindo-o e atingindo as pessoas da terceira idade desde fases anteriores da vida. Com materiais simples e de baixo custo, no projeto de intervenção, se alcançou o lazer-educação e a educação para o lazer de forma satisfatória
\end{abstract}

Palavras-chave: Terceira Idade. Lazer. Lazer-Educação. Educação Física.

\section{Leisure in the third age: human development and quality of life}

\begin{abstract}
The article aimed to understand the concept of leisure and understanding that older people have about their benefits to the quality of life as part of the idleness of the population. We used a sample of subjects living in the city of Bauru, SP, aged less than fifty years, of both sexes and economically disadvantaged class. It was used in literature, documentary and field. We developed an intervention project that aimed to education for leisure. It was the conclusion that public policies are necessary and qualified professionals for construction projects and equipment to expand the Recreation, spreading it and reaching the people of old age since previous stages of life. Materials with simple and low cost, the project of intervention, it reached the recreation-education and education for leisure satisfactorily.
\end{abstract}

Key Words: Third age. Leisure Recreation. Education Physical. Education.

\section{Introdução}

A pesquisa proposta foi desenvolvida pelo fato das pessoas da terceira idade, principalmente aquelas desfavorecidas economicamente terem pouca ou nenhuma oportunidade de ocupar o tempo livre, de modo a obterem melhoria em seu bem estar social e saúde com equilíbrio biopsicosocial. Dessa forma, se buscou diferentes maneiras de conhecer e vivenciar o lazer não dissociado da Educação, tanto nas vivências como fora delas, fosse criando hábitos ou as necessidades de se ter um tempo para descansar e se divertir se desenvolvendo, saindo da rotina das obrigações do dia-a-dia, mesmo nos encontros, para apropriação dos conceitos sobre lazer, saúde e Educação.

Este artigo investigou os moradores do Bairro Ferradura Mirim, da cidade de Bauru-SP, adultos com mais de cinqüenta anos de idade, que na

\footnotetext{
${ }^{1}$ Membro do Núcleo de Estudos e Pesquisas e Preparação Profissional em Educação Física (NEPEF) - . UNESP - Univ Estadual Paulista, Campus de Rio Claro, SP, Brasil; Grupo de Estudos e Pesquisas em Preparação Profissional em Educação Física (GEPPEF) da FEF-UNICAMP, Capinas, SP, Brasil e Grupo de Pesquisa em Lazer (GPL) da UNIMEP, Piracicaba, SP, Brasil
}

maior parte de suas vidas, trabalharam e não tiveram oportunidade de exercerem o direito ao lazer.

Além de se adaptarem a uma nova fase, a da aposentadoria, os idosos não tinham opções para ocuparem o tempo livre que aumentou na fase vivida por eles e isso se deu pela falta de equipamentos de lazer, como praças, áreas de lazer, centros comunitários, casas de cultura, entre outros, por insuficiência de políticas públicas no bairro, que se localiza na periferia da cidade de Bauru-SP.

O objetivo desta pesquisa foi compreender a visão de lazer e o entendimento dos sujeitos sobre seus benefícios para suas vidas.

Houve interesse por perceber se no tempo de vida e na cultura de cada um, houve possibilidade de usufruto do tempo-livre com o lazer, ou se o tempo-disponível era reutilizado para mais e mais obrigações. Observar se tiveram contato com os grupos de interesses/conteúdos do lazer, expostos inicialmente por Dumazedier (2001) e ampliados posteriormente por Marcellino (1998) e Camargo (1992). 
Este artigo resulta de estudos compartilhados com o Grupo de Estudos e Pesquisas em LazerEducação - GEPLE - FC/UNESP - Campus de Bauru, que entre outras atividades desenvolve projetos de pesquisa e extensão com temáticas variadas que incluem pessoas de todas as faixas etárias.

Constou da metodologia, aplicação de pesquisa diagnóstica, seguida de projeto de intervenção, visando à Educação para o Lazer e posteriormente se realizou nova pesquisa de campo, com a finalidade de compreender se os participantes perceberam benefícios do lazer para suas vidas. Se houve a conscientização da importância do lazer, alterando as rotinas diárias dos participantes, para que estes sentissem mais prazer em usufruir da fase de vida em que se encontravam.

Segundo Dumazedier (1994), o lazer tem como função importante a tentativa de fazer com que 0 indivíduo se desligue temporariamente de suas obrigações. Assim houve pretensão que os sujeitos experimentassem essa sensação, na tentativa de libertá-los de suas rotinas obrigações, para expor seus sentimentos e emoções.

Concluiu-se que os participantes que eram oriundos de diversas regiões do país não tiveram oportunidades de acesso à Educação para o Lazer,em fases anteriores à do desenvolvimento do projeto e que suas visões sobre o lazer eram bem restritas.

Que suas vidas foram de trabalho árduo e que as obrigações permanentes os alijaram de contato com o lazer, dificultando seu entendimento, bem como a sua valorização.

Concluiu-se também que não possuíram acesso a políticas públicas de lazer e também na terceira idade, em que possuíam mais tempo livre. Porém, mais dificuldades de exercerem 0 direito ao lazer.

Com a pesquisa puderam de forma lúdica, demonstrar a visão predominante de lazer, assimilar conceitos e valores relativos ao lazer, à saúde e à Educação, alterando posicionamentos quanto ao uso do tempo e revalorização da fase de vida vivenciada.

\section{Lazer, terceira idade e sociedade}

Para a terceira idade, o lazer como fenômeno social, é significativo, pois, coincide em muitos casos com a aposentadoria, em que poderiam usufruir do lazer visto como:

$$
\text { ...um conjunto de ocupações as quais o }
$$$$
\text { indivíduo pode entregar-se de livre vontade, }
$$

seja para repousar, seja para divertir-se, recrear-se e entreter-se ou, ainda para desenvolver sua informação ou formação desinteressada, sua participação social voluntária ou sua livre capacidade criadora após livrar-se ou desembaraçar-se das obrigações profissionais, familiares e sociais. ( DUMAZEDIER, 2001, p. 132)

Ao tratar da fase da aposentadoria Bruhns (1997) cita como sendo uma faixa etária desprivilegiada, por ter um decréscimo no salário, pelo fato dessa renda para os aposentados, no Brasil, ser insuficiente para manter as famílias com o mesmo nível/patamar que tinham quando em fase produtiva.

Assim, muitas pessoas ainda desempenham algum tipo de atividade que gere renda por necessidade de sobrevivência (DUMAZEDIER, 1994).

Dessa forma, o problema da falta de lazer para pessoas da terceira idade é de qualquer classe social, mas, sobretudo, daquelas desfavorecidas economicamente por falta de agregação da cultura do lazer, por meio da Educação para o Lazer.

Bruhns (1997) cita como dificuldade ao acesso do lazer, pelas camadas desfavorecidas, a necessidade de cumprir horas-extras no trabalho, preços inacessíveis dos ingressos para apreciação de eventos de caráter cultural, além de dependência de transportes coletivos e a longa distância do lar para os centros de lazer.

Socialmente decorre do modo vigente, se valorizar a atividade produtiva - trabalho, enquanto rendimento, geração de riquezas e lucro. Assim, segundo Dumazedier (1994), muitos aposentados preferem ou necessitam continuar trabalhando, como forma de se manterem financeiramente independentes. Quando não mais trabalham não sabem atribuir valor ao tempo-livre e ao que nele podem vivenciar de positivo para as suas vidas.

O fato de não terem tido acesso a conhecimentos sobre lazer e nem vivenciado o Lazer - Educação na escola ou fora dela, interfere negativamente na história do cidadão, que ao chegar à terceira idade se vê impossibilitado muitas vezes de adquirir novos hábitos.

A hipótese com a qual se trabalhou foi a de que os idosos moradores do bairro Ferradura Mirim de Bauru-SP, sujeitos pesquisados, tiveram pouca oportunidade de contatar conhecimentos que Ihes conferissem uma compreensão mais aprofundada sobre o lazer, porque faziam parte da classe trabalhadora, que foi excluída de uma Educação sistematizada para esse fim. 
Isso inclui a Educação Física escolar que não Ihes proporcionou entendimento de sua importância para seu desenvolvimento humano e social, relacionamento com o prazer lúdico e proximidade com o Lazer - Educação.

Com o envelhecimento há a chegada de uma nova fase de vida, que mesmo se considerando as diferenças socioculturais, são marcadas por preconceitos, estigmas e desvalorização familiar e social, dado o decréscimo da vida produtiva, ligada ao trabalho. Assim, os idosos se não tiverem uma aceitação em relação à chegada da aposentadoria e problemas decorrentes da idade, poderão viver uma fase de dificuldades de ordem física, social e psíquica (PONT GEIS, 2003).

Essa falta de aceitação se dá pelo fato da aposentadoria para a maior parte da população brasileira ter se revelado insuficiente para prover necessidades básicas dos idosos, não lhes dando a segurança suficiente para viverem de forma mais estável.

Assim, as políticas públicas podem representar uma saída para sanar esse déficit.

Dessa forma, o lazer tem um papel importante, proporcionando que os idosos tenham uma vida mais descontraída, com mais socialização, podendo interagir com outras pessoas e culturas, participando da vida social, assumindo compromissos de modo enriquecedor e criativo com conseqüente inserção no meio sociocultural, já que segundo Pont Geis (2003) com o passar dos anos, a tendência é que os idosos se afastem de seus familiares, fiquem longe de seus entes queridos.

O lazer tem um papel significativo, pois, é possível de se realizar no tempo livre fora do tempo das obrigações, em que as pessoas podem se expressar, sentirem prazer, utilizaremse de sua criatividade para se divertirem, descansarem e se desenvolverem e que pode agregar sujeitos com desejos e necessidades semelhantes, num mesmo ambiente (BRAMANTE, 1998). Sendo assim, tem relevância para as pessoas da terceira idade no contexto social estudado.

\section{A imprescindibilidade das políticas públicas de lazer}

Como a aposentadoria se constitui em fator que influencia a vida do indivíduo e a vida social, esta se torna um tema importante também para as políticas públicas (SALZEDAS e BRUNS, 2007).

$\begin{array}{cccc}\text { Lembramos } & \text { que } & \text { no } & \text { momento da } \\ \text { aposentadoria } & 0 & \text { lazer } & \text { para } \\ \text { a terceira idade }\end{array}$

deveria se tornar primordial, pois, a ocupação do tempo com atividades que propiciem 0 seu desenvolvimento, resulta em benefícios para os idosos e a sociedade como um todo.

Segundo Dumazedier (1994) observa-se que as atividades que predomina no tempo livre da maioria dos idosos, são quase sempre as mesmas que as que foram praticadas no tempo livre durante a vida ativa. Elas continuam, com um ligeiro aumento na sua duração e freqüência, mas sofrendo adaptações. São atividades que se tornam um modo de resistência ao envelhecimento.

As políticas sociais no Brasil não têm sido alvo importante para as administrações públicas, mas tem havido mudanças no sentido que Pinto (2008, p. 43) aponta "...quando falamos em políticas sociais, tratamos de ações que garantam os direitos dos cidadãos...". Ainda Pinto (2008, p. 08) expõe: "...o Estado tem algumas de suas leis ligadas ao exercício da cidadania das pessoas...", que são inovações na gestão das políticas sociais brasileiras, considerando o lazer como direito de todos (PINTO, 2008).

De acordo com Marcellino (2008 a) o lazer deve ser levado em conta, por ter um duplo aspecto educativo, como forma de desenvolvimento pessoal e social, além do descanso e divertimento, de forma que se tenham mais ações em relação às políticas de Lazer, ou seja, tentar observar as relações entre este e a Educação, Saúde, e a Promoção Social.

Algumas das inovações a serem realizadas são: primeiro, em relação à justiça social e cidadania que visa a democratização da gestão pública e superação de barreiras, promovendo a inclusão com justiça e acessibilidade a diversificadas oportunidades de lazer. E a outra, seria o compromisso político com a inovação, isto se dá pelo fato se ter ambientes que sejam favoráveis em relação à população beneficiária, aos dirigentes e servidores, a fim de concretizar mudanças efetivas (PINTO, 2008).

Para Marcellino (2008 a), para que se faça do Lazer um instrumento de participação cultural, é preciso ter incentivo do poder público nos diferentes grupos sociais para manifestações culturais, para que haja envolvimento destes e, conseqüentemente uma superação de visões superadas, para formação de pessoas críticas e criativas.

Mas, como grande desafio no campo do lazer, deve-se fazer muito, para que as mudanças sejam feitas no Brasil, pois, implicam em transformações culturais, políticas, conceituais e 
de valores atribuídos ao lazer e às práticas políticas.

O paradigma dominante no campo das políticas sociais tem como objetivo principal considerar os direitos sociais, ou seja, o atendimento das necessidades básicas de todos os cidadãos com base nos princípios da inclusão e eqüidade (PINTO, 2008) que seria 0 atendimento às necessidades diferenciadas dos sujeitos e grupos por meio de ações que amenizem as diferenças.

Uma mudança do paradigma quanto ao objetivo buscado hoje pelas políticas sociais se traduz na compreensão das políticas de lazer não mais almejarem o preenchimento do tempo ocioso das pessoas, mas como ação que influi na constituição de identidades individuais e coletivas, de corpos em movimento, que sofrem influência das condições de homem, mulher, jovem, idoso, negro, com diferentes habilidades corporais e outras especificidades (PINTO, 2008).

Sendo assim, as políticas de lazer devem superar barreiras que possam dificultar ou impedir o acesso dos usuários. Para isso é preciso construir e manter os espaços e equipamentos, propiciando infra- estrutura adequada, profissionais para o planejamento e a gestão capacitados e também que se preserve a natureza, para ampliar a acessibilidade ao lazer (PINTO, 2008).

Marcellino (2008 c) aponta também a necessidade de se ter profissionais competentes na área, que compreendam as interfaces do lazer, para que sejam trabalhados os diferentes conteúdos culturais do lazer. Destes profissionais se espera... "que se respeite o conceito de lazer e conjugue difusão e participação culturais" (p. 27) e ainda que se envolvam ..."pela participação efetiva no planejamento, execução e avaliação dos programas e dos equipamentos de lazer da cidade..." (p. 27).

Para que sejam realizadas plenamente as políticas é necessário diagnosticar a realidade dos beneficiários das políticas, a conscientização dos gestores e também da população a ser atendida, com um acompanhamento sistemático da ação, com vistas a verificar a adequação de seus objetivos, metas e metodologias, tendo em vista o resultado que se deseja atingir com a ação (PINTO, 2008). Marcellino (2008c), completa, relatando a necessidade de que o profissional se adeque ao tempo disponível da clientela, e não o contrário, dessa forma haverá um atendimento maior à população e difusão do Lazer.
Quanto à lógica de tomadas de decisões, refere-se a uma sociedade que se regula a partir do mercado, impõe um padrão de sociabilidade individualista, privatista, competitivista, deixando os valores da democracia e cidadania com espaços restritos. Assim, para a tomada de decisões, há participação ativa dos próprios usuários dos sistemas de forma que seja restrita ou ampliada. A participação restrita caracteriza-se pelo envolvimento da comunidade diretamente beneficiada em um projeto político local, enquanto que a participação ampliada refere-se à capacidade dos grupos organizados de influenciar, direta e indiretamente, nas políticas de forma a reestruturar ou implementar seus programas.

Para Marcellino (2008b), uma alternativa válida é a ação comunitária, que se assemelha com a "participação restrita" citada acima. Mas para isso, é preciso um desenvolvimento no setor, como as características e interesses das pessoas do local, conjuntamente buscar apoio dos poderes públicos e privados locais.

\section{Metodologia}

Nesta pesquisa nos apoiamos em Lakatos e Marconi (2001) que ajudam a caracterizá-la como de observação direta extensiva, em que se coletou dados por meio de questionários e que foram aplicados no início e no final do cronograma com o objetivo de apreender o que era o lazer para os sujeitos participantes, a importância e a necessidade de se ter lazer.

Desenvolveu-se um projeto de intervenção com vivências do lazer, da Educação para o Lazer e do Lazer- Educação.

Os questionários tiveram algumas questões abertas, que de acordo com Dumazedier (2001), Marcellino (2002) e Camargo (1992) se trata de conhecimentos mais específicos sobre lazer, para se obter um aprofundamento maior sobre o tema proposto, e também perguntas fechadas, ou seja, de múltipla escolha.

No projeto de intervenção atuou-se com os interesses manuais, sociais, turísticos, físicoesportivos, intelectuais e artísticos (CAMARGO, 1992).

Os pesquisadores freqüentaram 0 bairro Ferradura Mirim semanalmente e, em contato com o grupo desenvolveu de forma indissociada a pesquisa e a extensão.

Todos interessados podiam participar, desde que tivessem cinqüenta anos ou mais de idade.

O grupo de participantes oscilou em número, mas não ultrapassou quinze freqüentadores. Eles 
viviam em condições muito negativas/marginalizantes, e os pesquisadores os convidavam indo de casa em casa (barracos). Também se contou com apoio de uma Assistente Social ligada à Casa Amorós (instituição religiosa), que possuía um galpão que era cedido para as universidades desenvolverem propostas de pesquisa e extensão.

As avaliações da extensão foram realizadas pelo grupo conjuntamente.

Tal estudo pode proporcionar a coleta de dados que ajudou na confirmação da hipótese de que pessoas de classe desfavorecida, da terceira idade, sobretudo, necessitam de políticas públicas de lazer, que as atendam a contento.

Dessa forma, os resultados foram analisados a partir dos dados obtidos na pesquisa de campo, por meio dos questionários, quando abordados à luz da pesquisa teórica, em que foi feita a avaliação da evolução ou não por parte dos participantes e também se havia alcance dos objetivos almejados.

Os moradores em sua maioria pertenciam a várias partes do Brasil e vieram para a cidade com intuito de melhorar as condições de vida, em busca de trabalho. Tiveram uma vida árdua, e necessitavam de apoio por meio de políticas públicas e privadas que tivessem como objetivo oferecer um programa de Educação através e para o lazer, e conseqüentemente melhoria na qualidade de vida que os proporcionasse saúde, bem estar e Educação de forma prazerosa.

Os idosos do bairro, na maioria das vezes, ficavam em suas casas exercendo as atividades diárias, como, cuidar da casa, dos netos e outros afazeres, deixando de ter uma relação social mais próxima com as pessoas do próprio bairro, ou de outros locais do município e de outras cidades. Muitos viviam isolados e se recusavam a qualquer participação social.

No início do projeto, em 2007, tivemos oportunidade de contatar os moradores, indo de casa em casa, para convidá-los e averiguou que muitos não tinham ânimo e interesse, se mostrando apáticos e desmotivados pela vida em comunidade. Também foram verificadas as condições socioeconômicas do local. Iniciou-se com uma adesão de oito participantes. Ao longo do projeto, houve três desistências, depois mais duas, uma por falta de interesse, e a outra por motivos de saúde, no qual o participante teve complicações e não pôde mais participar. O maior número de participantes alcançado foi quinze.
Sobre a pesquisa bibliográfica, foi realizado um estudo aprofundado sobre os temas: lazer, terceira idade e políticas públicas.

Em seguida, através dos principais autores pesquisados, como Dumazedier (1994), Marcellino (1998) e Camargo (1992), foram formulados questionários. $\mathrm{O}$ primeiro com questões diagnósticas e para num segundo momento, ser comparado com outro questionário que foi aplicado após o projeto de Educação para o Lazer (intervenção).

A intervenção, também organizada a partir dos autores estudados, foi realizada através de atividades da cultura do grupo, com metodologias respeitando a cultura deles.

Concomitantemente com o projeto de intervenção, ainda realizava-se pesquisa documental, com objetivo de superar os conceitos e/ou "pré-conceitos" que foram formados antes dessa leitura aprofundada. Assim, buscou-se superar o senso comum, constituído em barreira que limitava o conhecimento e a verdadeira essência do Lazer e sua legitimidade constitucional.

O desenvolvimento do projeto se deu a partir de um cronograma que sofreu pequenas alterações e que demonstrou a evolução dos participantes do com gradativo entendimento da importância do lazer e compreensão dos processos pelos quais passaram ao longo da vida que definiram a sua constituição atual. Da importância de ter uma postura mais livre e menos preconceituosa em relação ao tempo livre, ao lazer e ao lúdico, pois, sentiam a necessidade de participar como prazer benefício para a saúde e o bem-estar.

Os encontros eram feitos em ambiente lúdico, não havendo cobrança, tentando se aproximar ao máximo das concepções do Lazer, e deixando que os indivíduos tivessem liberdade para se expressarem.

Com isso, foi possível ter maior captação dos dados, com mais riqueza, pois, os participantes se sentiam a vontade para relatarem histórias da infância e vida adulta, como foram educados e como viveram. Através dessa aproximação ficou mais fácil confirmar-se a hipótese e a justificativa do presente trabalho.

Além de obterem conhecimento sobre a importância do Lazer, os participantes criaram uma nova rotina diária, melhorando o bem estar e a conscientização sobre a necessidade de se ter Lazer com qualidade. 
Também, houve uma melhoria no humor, em relação ao início, pois, chegavam sérios e com receio de fazer os relatos e vivências, e com o passar do tempo, foram se descontraindo e, apesar de os indivíduos se conhecerem, tiveram uma aproximação, aumentando a intimidade e a sociabilidade entre eles.

Após a intervenção, aplicou-se o segundo questionário para realização de estudo comparativo. Estes apresentaram resultados satisfatórios, pois, os indivíduos se mostraram muito interessados e empenhados, superando o entendimento inicial sobre o lazer e demonstrando necessidade de mudar o cotidiano, valorizando o bem-estar pessoal, o tempo livre e o desenvolvimento individual no lazer.

\section{Resultados e Discussão}

De acordo com o objetivo do estudo que foi o de compreender a visão sobre o lazer que tinham os participantes, bem como sua aceitação, nessa fase de vida, os dados coletados através dos questionários aplicados no início da pesquisa e no final da aplicação do projeto de intervenção, com duração de quatro meses, em que os pesquisadores proporcionaram vivências de lazer através dos grupos de interesses demonstraram que os sujeitos não tinham clareza sobre o lazer, sua história, necessidade e significado para a formação dos indivíduos. Também se constatou que houve uma absorção do lazer pois, perceberam a sua necessidade no meio social.

Algumas vivências foram inéditas para alguns sujeitos, como jogar baralho e assistir a filmes no cinema.

Ainda que, no início não houvesse plena participação; durante todo o período da pesquisa, frisavam que enquanto estavam em atividades conseguiam se libertar das obrigações que tinham em suas casas, e assim, fixavam o pensamento no que realizavam, sentiam-se bem e tinham prazer.

Sentiram a necessidade de inclusão de atividades, que anteriormente ao projeto de intervenção, não davam ou não havia importância para eles. Dedicaram mais tempo para "não fazerem nada". Também entenderam que "tempo livre" é o tempo de não ter obrigações e que nele podem se desenvolver através do lazer.

Como cita Dumazedier (1994, p. 141), tempo livre é:

...conjuntos de intervalos de tempos que se dá entre os tempos obrigatórios impostos pela sociedade e que retornam sem cessar a cada manhã ou a cada segunda-feira, ou a cada volta das férias e que são pagas pelo mais importante dos tempos obrigatórios: o tempo de trabalho profissional.

Quando se relacionaram em diversas atividades nas quais estavam inseridos os diferentes grupos de interesse do Lazer, segundo Camargo (1992), os sujeitos participantes, aumentaram o rol de atividades, ampliando a cultura vivenciada e o cuidado pessoal.

“... L Lazer tem o poder de aproximar as pessoas...", “...Tem a capacidade de fazer descobrir novas coisas...", foram algumas das respostas mais expressivas dadas pelos participantes em relação à importância do lazer para eles, após as vivências no projeto de pesquisa.

$E$, unanimemente, responderam que se 0 Lazer lhe fosse apresentado em fases anteriores, teriam uma vida com mais alegria, saúde e bem estar.

Dessa forma, através do desenvolvimento do projeto foi possível constatar observar que não são necessários grandes investimentos para implementação de lazer, pois, foram realizadas vivências atividades com materiais alternativos, recicláveis (dobraduras em papel), viagens de baixo custo, entre outros, e, sobretudo sem perder a ludicidade e o prazer, pois as propostas eram discutidas e definidas no grupo, com desprendimento do caráter obrigatório.

As diversas formas de usufruto do lazer, não necessitam unicamente de locais especiais, distantes dos próprios lares, mas sim, na essência que cada vivência pode ter para cada um, pois, como escreve Marcellino (2002, p. 08), ..."caracteriza o tipo de relação verificada entre o sujeito e a experiência vivida, basicamente a satisfação provocada pela atividade".

O idoso enfrenta diversas barreiras no usufruto do lazer e para que isso não ocorra é urgente uma educação para o lazer que estimule as pessoas por toda a vida.

Dessa forma, o projeto de pesquisa pôde revelar que os idosos não tiveram uma Educação para o Lazer, estavam sempre preocupados com as tarefas - familiares, sociais ou religiosas, deixando de lado as atividades que gostavam e muitas que nem tinham tido oportunidade de conhecer. A partir da vivência do Lazer começaram a sentir necessidade de mudar a rotina diária, disponibilizando maior tempo para o lazer.

$\mathrm{Na}$ pesquisa de campo os indivíduos relataram que quando eram mais jovens gostavam das mesmas atividades que ainda realizavam fazem, 
como, viajar, cuidar de plantas, irem às festas, cantar, pescar, entre outros, e ainda realizavam, como viajar, cuidar das plantas, irem às festas, cantar, pescar, entre outros, e ainda continuavam a realizá-las, porém, com muito menor freqüência.

Assim, os dados coletados, cotejados com a literatura pesquisada foram muito importantes, pelo fato de que se pode constatar que ainda persistem problemas que para serem solucionados há necessidade de se fazer valer os direitos dos idosos e o desenvolvimento educacional que contribua para a diminuição dos preconceitos em relação a esta vida fase de vida, pois, na maioria das ocasiões..."rejeitam o próprio corpo, julgando-se feios e incapazes, mascarando o aspecto mais positivo que é o viver ou o estar corporalmente vivo" (SIMÕES, 1998, p. 64) e também "a maioria se mostra desencantada por não saber gerenciar com prazer a existência sem uma ocupação profissional" (SALZEDAS e BRUNS, 1997, p. 16).

Desse modo, há urgência de políticas sociais que, para Pinto (2008) são... "ações que garantam os direitos dos cidadãos" (p. 43), e os direitos sociais como "direitos ao bem-estar econômico, à saúde, educação, aposentadoria, ao lazer, ou seja, bem-estar social previsto pela Constituição" (p. 44).

Ficar com tempo livre sem desenvolvimento pessoal, causa ociosidade e, sentimentos de inutilidade e desânimo, mas com a inclusão do lazer, os idosos participantes do projeto tiveram no seu tempo livre, oportunidades de se desenvolverem, e de se envolverem como meio em que viviam. ou seja, sentiam mais disposição para realizar as obrigações do dia-a-dia, relacionaram-se com outras pessoas, que possuíam interesse por outros conteúdos do lazer.

Também, é preciso estimular os idosos a vivenciarem o Lazer, fazer com que mudem suas rotinas, freqüentem equipamentos que propiciem momentos de prazer e socialização, e conseqüentemente uma interação com outros sujeitos, de interesses semelhantes ou não.

É preciso coletar informações sobre os indivíduos e as características locais, onde será efetuada a intervenção, e também buscar apoio do poder público visando superar o assistencialismo, para alcançar uma Educação para o Lazer.

Em relação às vivências não foi preciso ter investimentos materiais de grande monta, pois a baixo custo se construiu, se inventou e criou conjuntamente os objetos utilizados pelo grupo.
Os idosos se mostraram interessados, por terem participado das vivências que despertaram a curiosidade e o entusiasmo neles.

O objetivo foi alcançado, pois, se conseguiu obter as informações relativas ao conhecimento sobre o lazer que se mostrou bem restrito, e a partir disso se atuou desenvolvendo o projeto de intervenção com os participantes, que vivenciaram os diferentes grupos de conteúdos.

Houve a Educação para o Lazer pois, os participantes sentiram a necessidade de mudar sua rotina, quiseram ter mais Lazer, sentiram-se bem mais satisfeitos após a participação no projeto de intervenção.

Portanto, é preciso que as políticas públicas proporcionem equipamentos e profissionais qualificados para se possa expandir o lazer para além do doméstico, na terceira idade, sem perder de vista o descanso, o divertimento e o desenvolvimento (DUMAZEDIER 2001).

Conclui-se que a Educação Física é uma área que pode contribuir positivamente para 0 processo de Educação para o Lazer e de LazerEducação e que os sujeitos investigados participantes da pesquisa não tiveram essa oportunidade ao longo de toda a sua trajetória de vida, fosse na escola ou na Educação informal, haja vista muitos terem tido muito pouco acesso ao ensino formal e mesmo quando o tiveram, não foi possível acesso à Educação para o Lazer por restrições de natureza sociocultural, econômica e profissional.

\section{Referências}

BRAMANTE, A. C. Lazer: concepções e significados. Licere, Belo Horizonte, vol.1, $\mathrm{n}^{\circ}:$, p.09-17, 1998.

BRUHNS, H. T. Introdução aos estudos do lazer. Campinas, SP: Ed da UNICAMP, 1997.

CAMARGO, L. O. de L. O que é lazer. $-3^{\underline{a}}$ ed. São Paulo: Brasiliense, 1993.

CAMARGO, L. O. de L Educação para o lazer. São Paulo: Moderna, 2001.

DUMAZEDIER, J. A revolução cultural do tempo livre. São Paulo: Estúdio Nobel. SESC, 1994.

DUMAZEDIER, J. Lazer e cultura popular $-3^{\mathrm{a}}$ ed. - São Paulo: Perspectiva, 2001.

DUMAZEDIER, J. Sociologia Empírica do Lazer. São Paulo: Perpesctiva: SESC, 1999. 
Estatuto do Idoso. Disponível em: http://www.senado.gov.br/web/relatorios/destaque s/2003057rf.pdf . Acessado em: 12 de Nov 2007.

LAKATOS, E. M.; MARCONI, M. A. Fundamentos de Metodologia Científica $-4^{\text {a }}$ ed. São Paulo: Atlas, 2001.

MARCELLINO, N. C. Lazer e educação.

Campinas, SP: Papirus, 1987.

MARCELLINO, N. C. Lazer: concepções e significados. Licere, Belo Horizonte, vol.1, $\mathrm{n}^{\circ}$ : 1, p.37-43, 1998.

MARCELLINO, N. C. Estudos do lazer: uma introdução. $-3^{\mathrm{a}}$ ed. - Campinas, SP: autores associados, 2002

MARCELLINO, N. C. Políticas de Lazer: Mercadores ou educadores? Os cínicos bobos da corte. In: MARCELLINO, N. C. (org). Políticas Públicas de Lazer. Campinas: Alínea, Cap. 3, p. $21-41,2008 c$.

MARCELLINO, N. C. Pressupostos de ação comunitária: Estrutura e canais de participação. In: $\therefore$ Alínea, Cap. 2, p. $17-19,2008 b$.

\section{MARCELLINO, N. C. Subsídios para uma}

Política de Lazer: O papel da administração municipal. In: : Alínea, Cap. 1, p. $11-16,2008 \bar{a}$

PEREIRA, R. J. et al . Contribuição dos domínios físico, social, psicológico e ambiental para a qualidade de vida global de idosos. Revista de Psiquiatria do Rio Grande do Sul, Porto Alegre, vol. 28, n: 1, 2006. Disponível em: http://dx.doi.org/10.1590/S010181082006000100005 . Acesso em: 12 de Nov 2007.

PONT GEIS, P. Atividade Física na terceira idade: teoria e prática $-5^{\underline{a}}$ ed. - Porto Alegre: ArTmed, 2003.

PINTO, L. M. S. de M. Lazer: concepções e significados. Licere, Belo Horizonte, vol.1, $n$ ㅇ: 1, p.18-27, 1998.

PINTO, L. M. S. Estado e Sociedade na Construção de Inovações nas Políticas Sociais de Lazer no Brasil. In: MARCELLINO, N. C. (org).

Políticas Públicas de Lazer. Campinas: Alínea, Cap. 4, p. 43 - 78, 2008.

SALZEDAS, L. P.; BRUNS, M. A. de T. O corpo em Transformação: A silenciosa passagem pelo tempo. In: BRUNS, M. S. de T.; DEL MASSO, M. C. S. (orgs.). Envelhecimento
Humano: diferentes perspectivas. Campinas:

Alínea, 1997, p. 13 - 33.

SIMÕES, R. Corporeidade e Terceira Idade: A Marginalização do Corpo Idoso - $3^{\mathrm{a}}$ ed. Piracicaba: Edditora UNIMEP, 1998.

Esse artigo foi apresentado em Sessão Temática no VI Congresso Internacional de Educação Física e Motricidade Humana e XII Simpósio Paulista de Educação Física, realizado pelo Departamento de Educação Física do IB/UNESP Rio Claro, SP de 30/4 a 03/5 de 2009.

Endereço:

Luciene Ferreira da Silva

Rua Manoel Pereira Rolla, 12-55, apto 104

Vila Universitária

Bauru SP Brasil

17012-190

Telefones: (14) 3223.1534 (res.), (19) 9787.9077

(cel.) e (14) 9607.7719 (cel.)

e-mail: lucienebtos@ig.com.br luciene@fc.unesp.br.

Recebido em: 10 de fevereiro de 2009. Aceito em: 03 de abril de 2009.

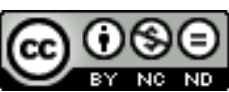

Motriz. Revista de Educação Física. UNESP, Rio Claro, SP, Brasil - elSSN: 1980-6574 - está licenciada sob Licenca Creative Commons 